\title{
Transactions
}

Cite this: Dalton Trans., 2011, 40, 11696

wWW.rsc.org/dalton

COMMUNICATION

\section{First structurally confirmed example of the formation of a gold(III) carbon bond via transmetallation with a boroxine $\uparrow$}

\author{
Gregory A. Price, Kevin R. Flower, * Robin G. Pritchard, Alan K. Brisdon and Peter Quayle \\ Received 1st August 2011, Accepted 26th September 2011 \\ DOI: 10.1039/c1dt11721a
}

Cyclometallated gold(III) complexes containing functionalised (2-dimethylaminomethyl)phenyl ligands have been prepared by transmetallation from boroxines to sodium tetrachloroaurate.

In 1931 Kharasch and Isbell ${ }^{1}$ reported the first preparation of aryl gold(III) complexes of the type $\left[\mathrm{ArAuCl}_{2}\right]_{2}$ by direct auration. Subsequent investigations by Liddle and Parkin ${ }^{2}$ addressed the instability of these dimeric gold(III) complexes, while de Graaf et al. ${ }^{3}$ and Puddephatt and Monaghan ${ }^{4}$ have outlined some of the limitations of the direct auration reaction. During the course of these studies it was observed that the auration reaction was inhibited by the presence of a weakly co-ordinating group on the arene. ${ }^{3,4}$ Currently the most common and versatile method of preparing cyclometallated aryl gold(III) complexes is via transmetallation from the relevant organomercurial. ${ }^{5-7}$ This reaction was used by Vicente and co-workers to prepare cycloaurated complexes of azobenzene and dimethylbenzylamine, ${ }^{8,9}$ which are inaccessible by direct auration. In the past twenty years there has been a resurgence of interest in preparing new cyclometallated gold(III) compounds for use in anticancer applications. ${ }^{10-24}$ This is due to the structural and electronic similarities between gold(III) and platinum(II). Numerous cyclometallated gold(III) complexes have been prepared via the organomercury route, ${ }^{6,7,25-31}$ and many show promising in vitro activity. However, the use of severely toxic organomercury compounds would preclude their potential use as chemotherapeutics.

Additionally the area of homogeneous gold catalysis has undergone enormous expansion in recent years, ${ }^{32-37}$ and is now at the forefront of transition metal catalysed reactions. Many of the catalytic reactions make use of proposed gold(I)/gold(III) redox systems to enable $\mathrm{C}-\mathrm{C}$ coupling with aryl boronic acids. ${ }^{38}$ One of the proposed coupling pathways involves transmetallation from the aryl boronic acid to gold(III), however no direct evidence of transmetallation to the gold(III) centre has been presented. Conversely Gray et al. have shown that aryl gold(I) compounds can be prepared via transmetallation from boronic acids under mild conditions. $^{39-42}$ This methodology gives comparable yields to the

School of Chemistry, University of Manchester, Manchester, UK, M13 9PL. E-mail:dr_kevin_flower@yahoo.co.uk

$\dagger$ Electronic supplementary information (ESI) available: Full experimental details. CCDC reference number 837221. For ESI and crystallographic data in CIF or other electronic format see DOI: 10.1039/c1dt11721a

classical organolithium based preparation of gold(I) complexes, and also tolerates a wide range of functional groups.

Herein we report a new synthetic route for the preparation of gold(III) compounds containing a 2-(N,Ndimethylaminomethyl)phenyl-based ligand by a new boron transmetallation route (Scheme 1) that avoids the use of toxic organomercurial reagents. The boroxines $\mathbf{1}-\mathbf{4}$ were prepared by the reaction of the corresponding lithium reagent with $\mathrm{B}(\mathrm{OMe})_{3}$ in THF or $\mathrm{Et}_{2} \mathrm{O}$ at $-78{ }^{\circ} \mathrm{C}$. Hydrolysis and aqueous work-up afforded the boroxines. The compounds were fully characterised by elemental analysis $(\mathrm{C}, \mathrm{H}$ and $\mathrm{N})$ and NMR spectroscopy $\left({ }^{1} \mathrm{H}\right.$, ${ }^{13} \mathrm{C}\left\{{ }^{1} \mathrm{H}\right\}$ and ${ }^{11} \mathrm{~B}\left\{{ }^{1} \mathrm{H}\right\}$ ), see ESI. $\dagger$ In addition crystals of $\mathbf{1}$ suitable for a single crystal X-Ray diffraction: study were obtained from dichloromethane/hexane.§

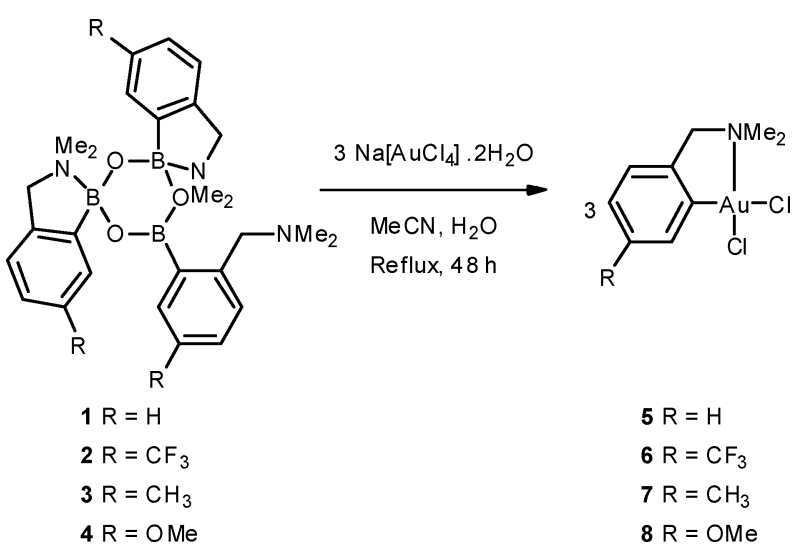

Scheme 1 The synthesis of compounds 5-8 from boroxines.

The gold(III) complexes 5-8 were prepared by addition of an aqueous solution of sodium tetrachloroaurate to the corresponding boroxine in $\mathrm{MeCN}$ and refluxing the yellow solution for $48 \mathrm{~h}$. Compounds 5-8 were fully characterised by elemental analysis (C, H and N), and NMR $\left({ }^{1} \mathrm{H}\right.$ and $\left.{ }^{13} \mathrm{C}\left\{{ }^{1} \mathrm{H}\right\}\right)$ spectroscopy, see ESI. $\dagger$ Compounds 5 and 7 were also further characterised by single crystal X-ray diffraction studies; 9 see Fig. 1 for an ORTEP representation of previously unreported 7 along with selected bond lengths $(\AA)$ and angles $\left({ }^{\circ}\right)$.

It has long been thought that transmetallation reactions involving gold(III) are extremely sensitive to the reaction solvent. ${ }^{11} \mathrm{We}$ believe that water plays a key role in transmetallation by hydrolysing the cyclic boroxine trimer. This would allow coordination of the 


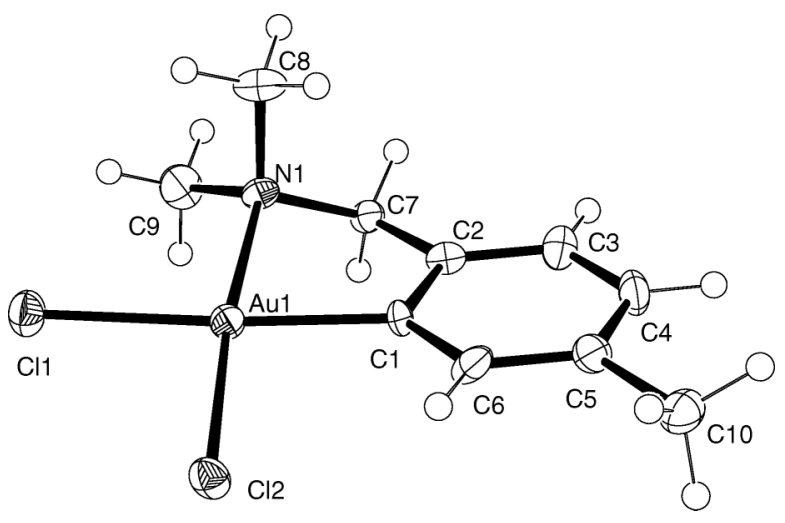

Fig. 1 ORTEP representation of $\left[\mathrm{AuCl}_{2}\left(\mathrm{\kappa}^{2}-\mathrm{C}, \mathrm{N}-\mathrm{C}_{6} \mathrm{H}_{4}-2-\mathrm{CH}_{2} \mathrm{NMe}_{2}-\right.\right.$

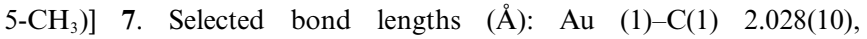
$\mathrm{Au}(1)-\mathrm{N}(1)$ 2.091(10), $\mathrm{Au}(1)-\mathrm{Cl}(1)$ 2.385(3), $\mathrm{Au}(1)-\mathrm{Cl}(2)$ 2.287(3); Selected angles ( ${ }^{\circ}$ : $\mathrm{Cl}(1)-\mathrm{Au}(1)-\mathrm{Cl}(2)$ 91.99(9), $\mathrm{Cl}(1)-\mathrm{Au}(1)-\mathrm{N}(1)$ 94.1(3), $\mathrm{Cl}(1)-\mathrm{Au}(1)-\mathrm{C}(1)$ 175.6(3), $\mathrm{Cl}(2)-\mathrm{Au}(1)-\mathrm{N}(1)$ 173.8(3), $\mathrm{Cl}(2)-\mathrm{Au}(1)-\mathrm{C}(1)$ 92.4(3), N(1)-Au(1)-C(1) 81.5(4).

free nitrogen to the gold centre prior to transmetallation. This is a similar mechanism to that postulated for organomercurial transfer; ${ }^{31}$ initial coordination of gold(III) to the free amine donor followed by cycloauration.

To summarise a new procedure for the preparation of cyclometallated gold(III) complexes containing a functionalised dimethylbenzylamine ligand is described. The reaction shows transmetallation from a boroxine to gold(III) in aqueous acetonitrile is effective for the formation of a gold(III)-carbon bond via transmetallation. These data should also enable greater understanding of the developing field of gold(I)/(III) redox catalysis. The yield is also comparable to that obtained via transmetallation from an organomercurial. It is also advantageous as it avoids the use of extremely toxic mercury compounds and may therefore enable further development of gold(III) organometallic antitumour agents.

Further investigations into the scope of this new methodology are ongoing.

\section{Notes and references}

$\$$ Data were collected on a Nonius $\kappa$-CCD 4-circle diffractometer, and the crystal structures were solved by direct methods, with full-matrix leastsquares refinement on $F^{2}$ using the SHELXL program. ${ }^{43}$

$\S$ Crystal data for 1: $\left(\mathrm{C}_{27} \mathrm{H}_{36} \mathrm{~N}_{3} \mathrm{~B}_{3} \mathrm{O}_{3}\right): M_{\mathrm{r}}=483.3$; orthorhombic, space group $P 2_{1} 2_{1} 2_{1}, a=8.9650(6), b=14.709(11), c=19.517(2) \AA$, and the data are comparable to that previously reported. ${ }^{44}$

ๆ Crystal data for 5: $\mathrm{C}_{9} \mathrm{H}_{12} \mathrm{NCl}_{2} \mathrm{Au}, M_{\mathrm{r}}=402.06$; crystal size $=0.22 \times 0.14$ $\times 0.14 \mathrm{~mm}$, monoclinic, space group $P 2_{1} / c, a=7.7340(3), b=9.4210(3)$, $c=15.0630$ (7) $\AA$ and $\beta=100.2530(10)^{\circ}$, and the data are comparable to that previously reported. ${ }^{45}$

Crystal data for 7: $\mathrm{C}_{10} \mathrm{H}_{14} \mathrm{NCl}_{2} \mathrm{Au}, M_{\mathrm{r}}=416.09$; crystal size $=0.05 \times 0.12$ $\times 0.16 \mathrm{~mm}$, monoclinic, space group $P 2_{1} / c, a=8.7402(3), b=11.1657(5)$, $c=16.9401(5) \AA$ and $\beta=135.074(2)^{\circ}$.

1 M. S. Kharasch and H. S. Isbell, J. Am. Chem. Soc., 1931, 53, 30533059 .

2 K. S. Liddle and C. Parkin, J. Chem. Soc.-Chem. Commun., 1972, 26 a.

3 P. W. J. de Graaf, J. Boersma and G. J. M. Vanderkerk, J. Organomet. Chem., 1976, 105, 399-406.

4 P. K. Monaghan and R. J. Puddephatt, Inorg. Chim. Acta, 1975, 15, 231-234.

5 J. Vicente, M.-D. Bermúdez, F.-J. Carrión and P. G. Jones, Chem. Ber,, 1996, 129, 1301-1306.

6 K.-H. Wong, K.-K. Cheung, M. C.-W. Chan and C.-M. Che, Organometallics, 1998, 17, 3505-3511.
7 K. J. Kilpin, W. Henderson and B. K. Nicholson, Inorg. Chim. Acta, 2009, 362, 3669-3676.

8 J. Vicente, M. T. Chicote and M. D. Bermudez, Inorg. Chim. Acta, 1982, 63, 35-39.

9 J. Vicente, M. T. Chicote and M. D. Bermudez, J. Organomet. Chem., 1984, 268, 191-195.

10 R. G. Buckley, A. M. Elsome, S. P. Fricker, G. R. Henderson, B. R. C. Theobald, R. V. Parish, B. P. Howe and L. R. Kelland, J. Med. Chem., 1996, 39, 5208-5214.

11 P. A. Bonnardel, R. V. Parish and R. G. Pritchard, J. Chem. Soc., Dalton Trans., 1996, 3185-3193.

12 M. B. Dinger and W. Henderson, J. Organomet. Chem., 1998, 560, 233-243.

13 M. B. Dinger and W. Henderson, J. Organomet. Chem., 1998, 557, 231-241.

14 W. Henderson, B. K. Nicholson, S. J. Faville, D. Fan and J. D. Ranford, J. Organomet. Chem., 2001, 631, 41-46.

15 C. H. A. Goss, W. Henderson, A. L. Wilkins and C. Evans, J. Organomet. Chem., 2003, 679, 194-201.

16 L. Messori, G. Marcon, M. A. Cinellu, M. Coronnello, E. Mini, C. Gabbiani and P. Orioli, Bioorg. Med. Chem., 2004, 12, 6039-6043.

17 M. Coronnello, E. Mini, B. Caciagli, M. A. Cinellu, A. Bindoli, C. Gabbiani and L. Messori, J. Med. Chem., 2005, 48, 6761-6765.

18 G. Marcon, S. Carotti, M. Coronnello, L. Messori, E. Mini, P. Orioli, T. Mazzei, M. A. Cinellu and G. Minghetti, J. Med. Chem., 2002, 45, 1672-1677.

19 L. Messori, F. Abbate, G. Marcon, P. Orioli, M. Fontani, E. Mini, T. Mazzei, S. Carotti, T. O'Connell and P. Zanello, J. Med. Chem., 2000, 43, 3541-3548.

20 E. R. T. Tiekink, Crit. Rev. Oncol. Hematol., 2002, 42, 225-248.

21 E. R. T. Tiekink, Gold Bull., 2003, 36, 117-124.

22 L. Engman, M. McNaughton, M. Gajewska, S. Kumar, A. Birmingham and G. Powis, Anti-Cancer Drugs, 2006, 17, 539-544.

23 U. Abram, K. Ortner, R. Gust and K. Sommer, J. Chem. Soc., Dalton Trans., 2000, 735-744.

24 D. M. Fan, C. T. Yang, J. D. Ranford, P. F. Lee and J. J. Vittal, Dalton Trans., 2003, 2680-2685.

25 J. Vicente, M. T. Chicote, A. Arcas and M. Artigao, Inorg. Chim. Acta, 1982, 65, L251-L253.

26 J. Vicente and M. T. Chicote, Inorg. Chim. Acta, 1981, 54, L259L260.

27 E. C. Constable and T. A. Leese, J. Organomet. Chem., 1989, 363, 419-424.

28 E. C. Constable, R. P. G. Henney, T. A. Leese and D. A. Tocher, J. Chem. Soc., Dalton Trans., 1990, 443-449.

29 J. Vicente, M. T. Chicote, A. Arcas, M. Artigao and R. Jimenez, J. Organomet. Chem., 1983, 247, 123-129.

30 J. Vicente, A. Arcas and M. T. Chicote, J. Organomet. Chem., 1983, 252, 257-262.

31 W. Henderson, Adv. Organomet. Chem., 2006, 54, 207-265.

32 A. Corma, A. Leyva-Pérez and M. J. Sabater, Chem. Rev., 2011, 111, $1657-1712$.

33 A. S. K. Hashmi, Gold Bull., 2003, 36, 3-9.

34 A. S. K. Hashmi, Chem. Rev., 2007, 107, 3180-3211.

35 A. S. K. Hashmi and M. Rudolph, Chem. Soc. Rev., 2008, 37, 17661775.

36 Z. Li, C. Brouwer and C. He, Chem. Rev., 2008, 108, 3239-3265.

37 N. D. Shapiro and F. D. Toste, Synlett, 2010, 675-691.

38 N. P. Mankad and F. D. Toste, J. Am. Chem. Soc., 2010, 132, 12859 12861.

39 D. V. Partyka, M. Zeller, A. D. Hunter and T. G. Gray, Angew. Chem., Int. Ed., 2006, 45, 8188-8191.

40 D. V. Partyka, A. J. Esswein, M. Zeller, A. D. Hunter and T. G. Gray, Organometallics, 2007, 26, 3279-3282.

41 D. V. Partyka, J. B. Updegraff, M. Zeller, A. D. Hunter and T. G. Gray, Organometallics, 2009, 28, 1666-1674.

42 L. Gao, M. A. Peay, D. V. Partyka, J. B. Updegraff, T. S. Teets, A. J. Esswein, M. Zeller, A. D. Hunter and T. G. Gray, Organometallics, 2009, 28, 5669-5681.

43 G. M. Sheldrick, SHELXS-97, Program for solution of crystal structures, University of Göttingen, Germany, 1997.

44 J. C. Norrild and I. Sotofte, J. Chem. Soc., Perkin Trans. 2, 2002, $303-$ 311.

45 J. Mack, K. Ortner and U. Abram, Z. Anorg. Allg. Chem., 1997, 623, 873-879. 